\title{
Philosophical Connotations, Generating Logic and Construction Paths of Ecological Civilization in a Global View
}

\author{
Hongbo Wang \\ School of Marxism, Capital Normal University, Beijing 100048, China \\ whb7663@126.com
}

Keywords: Ecological Civilization,Ecological Crisis,Ecological Ethics,Generating Logic,Practice.

\begin{abstract}
The ecological civilization is a complex concept with content-rich and quantities of differences. After theoretical textual research, the definition of the concept of ecological civilization should reflect or abide by these five basic principles: relationship-oriented, people-oriented, process-oriented, positive orientation and overall orientation. The concept of ecological civilization is generated by the growing influence of the three-dimensional logic of reality and political theory. In the future path of Chinese ecological civilization construction, the individual values of the level of consciousness, the legal system intervention in the national level and in the boot of the social and moral education and exchanges and cooperation in the international level are the possible way out of the ecological crisis of remission or even survive the crisis, construct "ecological civilization" era.
\end{abstract}

\section{Introduction}

Currently, the ecological civilization has become a term of high frequency of political programs, academic research as well as public life. The reason is out of the ecological crisis and the crisis of human existence. In Chinese academic level, the ecological civilization appears to have become a generic term academic, but the concept to define, path generation logic to build and other aspects of a lot of disagreement still exist. Therefore, the research will clarify the issue of the concept to define, path generation logic to build and other aspects in China. Only in this way, the theory confidence in the depth of the political level shall be promoted; follow-up study in the academic level shall be fully extended; the practical aspects of implementing in the practice shall be truly implemented. This paper describes the connotation of Chinese philosophy of ecological civilization, and elaborated further promote political, academic, and other aspects of the practice. Finally, Construction paths corresponding to build a comprehensive ecological civilization.

\section{Ecological Civilization Learning Theory}

Contemporary theories of ecological civilization can be divided into ecological center, Modern anthropocentrism and ecological Marxism. In China, the raise of "ecological civilization" concept is earlier than the West. Ecologists Ye Qian Ji in 1984 firstly proposed the "ecological civilization" concept (Yan and Yang, 2009). In general, the "eco" means more natural state of being. "Civilized" means more progressive state of society. General analysis, "ecological civilization" refers to the situation to evaluate the relationship between life and life situation and the environment in order to progress as the framework of society, or point scale. Objectively speaking, this concept has made deep theoretical connotations(Taylor,1986).

The concept is the logical starting point for defining the research question. In recent years, Chinese scholars conducted a study of rational analysis and elucidation of "ecological civilization" concept from different disciplines and perspectives, forming a variety of answers to "ecological civilization" concept. Quantities of scholars believe that the core of the "ecological civilization" is the relationship between "man and nature" to construct a harmonious or civilized state played. Of course, scholars also believe that this concept should also include human beings, and social and human harmony with itself and other state or civilization. On the other hand, the "ecological 
civilization" in the "civilized" structure location problem. It also involves two dimensions: the vertical dimension, "ecological civilization".

In the lateral dimension, "ecological civilization" is independent of material civilization, political civilization and spiritual civilization(Holmes,1994). Objectively speaking, the above findings of scholars about the ecological civilization, "the concept of laying the necessary precondition and foundation for further study. However, due to the "ecological civilization" concept in theory, far from becoming more universal worldwide "paradigm", while in reality it is not yet reflected in its form the "typical state." Therefore, there are multiple answers to one side or at most only describe a level of "ecological civilization" concept.

Although the West has long existed similar to the idea and the concept of ecological civilization, but it does have a clear definition of fresh. As Hegel (2004) said: "the meaning of a defined and it is bound to prove only that it develops in other words, the results have only come from the definition of the development process in the end, I no longer along the academic research. For more general way to try to define the "ecological civilization", but try to give the basic principles of concept definition, which may be even more necessary and important. First, the relationship between the orientation of the principle, that the relationship between man and nature-centered orientation . Second, the people-oriented principle that person" in this subject as a starting point and destination point. Third, the process-oriented principle that defines the concept of orientation and trends should reflect the dynamic development of its four principles of positive orientation that the definition of the concept should reflect a positive, positive achievements of civilization. Fifth, the overall orientation of the principle that the definition of the concept should reflect systematic and holistic. Sixth, the ideal orientation principle that should be reflected in the forward-looking concept definition ideal prospects.

According to experts these principles, philosophy, ecology, sociology and other fields, can be on the "ecological civilization" concept is given in accordance with professional features and define their own research needs. Furthermore, with the "ecological civilization," the philosophy and ideology of development and maturation, the connotation of "ecological civilization" will become increasingly clear and to really show.

\subsection{Reality Logic: Human Survival Distress}

Since the 20th century, under the impetus of scientific and technological revolution, human subjectivity even swell dramatically enhanced. Corresponding to this, over the science and technology activities triggered a global, sustained, deep ecological crisis. The essence of the ecological crisis damaged ecosystems equilibrium, namely ecosystem "imbalances." For the ecosystem, "imbalances" and "balance" this is the norm. Partial, occasional "imbalances" state fully self-adjusting and restored through the ecosystem. However, the excesses of human activities "imbalances" state has far exceeded the carrying capacity of ecosystems themselves. Mankind, as one of the important elements of the Earth's ecosystem, feel the closest increasingly grave of "ecological crisis as a huge obstacle. Specifically speaking, the relationship between the presence of deterioration and breakage is caused by the existence of substantial survive the crisis, and thus appeal for real logic of ecological civilization.

First of all, there is a crisis of the entity. Human nature must rely on the material basis to maintain their survival and development. It should be noted that the inorganic world (nature) to the human condition and the base material. On this basis, the human role in the inorganic world (nature) to "work" the peculiar practices. Since the 20th century, with the "ecological crisis" deepening, the natural world, the chances of becoming less direct human enjoyment. Natural material information (required to maintain human life activities) are more difficult to obtain. Sunlight, air and water are the three core elements of supporting natural ecosystems. Now they are no longer clean as a natural entity exists. According to the logic analysis, human survival and development are inseparable from the nature of the material conditions and infrastructure(Foster,2000). However, substantial human and material conditions necessary infrastructure and human nature of the entity are no longer clean, even has seriously deteriorated. Correspondingly, fragile human life is extremely fragile existence 
has a certain degree of inevitability. Today, the epidemic spread to a wide variety of range, the degree of the depth of the frequent outbreak of epidemic diseases, malignant diseases is constantly spewing fragile is the best evidence of the existence of human life. Now, therefore, save "substantial presence" deteriorate, thereby saving the lives of human beings, became the theoretical and practical issues need to crack.

Secondly, the relationship between the existence of a crisis. In-depth analysis, deterioration "substantial presence" is extrinsic imaging ecological crisis, and "the relationship between the existence of a crisis" is the inherent nature of the ecological crisis. There is a crisis of specific terms "sexual relations," which contains two interrelated levels: one broken relationship between man and nature; in the other hand, interpersonal relationships break, who is one of the important elements of the natural ecosystem. For this reason, at the macro level, only be maintained between man and nature (including the various components of the natural internal) dynamic, balanced interaction between open and people can maintain their own survival and development. That is, on the one hand, people want access to their own survival in nature and material necessary for subsistence necessary; on the other hand, nature should have the ability to break down and digest of human activity waste. However, in the scientific and technological revolution pushed human subjectivity rising. Accordingly, the nature of any human has increasingly become the object of mercy, which became the instrument of satisfaction of human desires. The balance between state between man and nature. Objectively speaking, the amount of human knowledge has been rapidly increasing. However, the relationship between man and nature, the amount of knowledge of human nature and date of request surge, which resulted in human knowledge "unbalanced state." Extremely serious negative consequences: the relationship between man and nature break. Human life and isolates. Mumford (1983) proposed that the man will not have complete control of nature, but also completely separate himself from his organic habitat in accordance with the laws of ecology: between any one thing must be related kind of life can not be out of context, other life to exist independently. Since the relationship between man and nature break, and people's lives have been out of isolation. So, the emergence of the ecological crisis is worsening and has a certain inevitability. As Commoner(1997) thought that ss a Contact between biological and other creatures, and all creatures and other things around between the beginning and therefore maintain the overall interrupt each other's role and influence began to waver up, and in some places have already quit.

Interpersonal relationships break. And other life, humans only maintain relationships with and adapt to the environment, other life, they can survive and develop. However, with other life are different, the more important characteristics of the human is social. That human beings inevitably composed of community through the establishment of relationships, and then the relationship with the natural form of organization by "society" occur. Based on this analysis, the reason why the relationship between man and nature can not be confined to people breaking analysis of natural elements and their relationships, but to in-depth analysis of social relations between people. Macroeconomic terms, the nature of human existence homes. Within this homeland, status and distribution of material conditions is not balanced, but is limited. Therefore, in order to maintain and protect the people's own survival and development, in the selfish nature of the role, between people is bound to be brutal competition. Objectively speaking, breaking the relationship between people is the inherent nature of the ecological crisis. In other words, the relationship between people break accelerated fracture relationship between man and nature and the natural process of death. For this reason, the relationship between people (it is between countries, the epitome of the relationship between man and society) point of view, to explore solve the ecological crisis, save the crisis of survival is an important path to the construction of ecological civilization. Moreover, this perspective may be closer to the essence of the level of problem solving.

\subsection{The Theoretical Logic: A Double Shift of Academic Research}

With the deepening of the global ecological crisis, saving the ecological crisis and the crisis of survival, and exploring the theory of ecological civilization era became the focal point of academic research. In-depth study found that in theory, the study of ecological civilization, steering and 
steering ecological research ethics is to support the "ecological civilization" to generate another dimension. First, the study of ecological civilization turn(Richard and David, 1988). Civilization is marked degree of development and progress of human society important yardstick. Since entering the civilized society, mankind has gone through a stage of primitive civilization, agricultural civilization and industrial civilization. From the perspective of the relationship between man and nature, in the original period of civilization, human understanding of nature is extremely limited. Mainly relationship between man and nature in harmony for a simple situation (naturally dominant). Entered a period of agricultural civilization, human understanding of nature has improved. Humans began to fight and natural. Mainly relationship between man and nature as a simple opposition status (naturally dominant); Entered a period of industrial civilization, human understanding of nature is rapidly increasing, began large-scale renovation and conquer nature.

Mainly relationship between man and nature as a sharp opposition status (human dominance). In the era of industrial civilization, the contradiction between society and nature has become increasingly prominent. Thus the result is that on the one hand is the rapid growth of social wealth; on the other hand the increasing scarcity of natural resources and ecological environment is deteriorating. Facing reality, scholars come to realize that the generation and evolution of civilization is mutual coordination between social (relationships between people body) and nature, mutual accommodation and mutual passage of the dialectical process. However, in the era of industrial civilization, because too much emphasis on human subjectivity, initiative and people's own development and progress (the concept itself of human culture dictates), while ignoring the human (social) corresponding to the natural evolution of the law itself and the people dialectical relationship between nature and interdependence, and the resulting relationship between the fracture people (society) and nature. Instead, the natural ecosystem perspective, in man and nature, society and nature of the dialectical relationship to further promote the study of civilization issues that should be from an ecological perspective of nature or to review the extent and condition of civilization (natural civilization or ecological civilization ). Moreover, in today's globalized, the latter stressed that research should focus on academic research and is becoming an important direction(Labor,1973).

Secondly, the study of ecological ethics turning. In the history of ethics, to discuss the ethical issues surrounding the relationships between people are to expand, and is a man of value judgments. However, faced with the ecological crisis and the crisis triggered by the human existence, humans began to ask ourselves seriously consider whether mankind out of the crisis should bear the responsibility, to assume the manner and extent of the problem. In other words, should the introduction of ethical thinking problems in the relationship between man and nature (Lowi.. and Shaw,2000). Objectively speaking, the introduction of the ethical relationship between man and nature, the introduction of the natural world, to accept emotionally, to find the root causes of the full academic needs to have a relatively long process. The literature shows that the introduction of ethical thinking in natural areas did not achieve the same academic consensus, but the rise and rapid development of eco-ethics is an indisputable fact. Objective analysis, both natural and human existence is the existence of society, and therefore people must play its rightful role in man and nature, man and society relations so that the two series, it should bear the responsibility. According to the traditional view of ethics, only the presence of people set to social, ethical and thus can only be made by people within the framework of social relationships or relationships that shackles so that both the development of ethics, but also limits the human development . Moreover, the significance of the issue of human values is by no means an abstract universal, its existence will inevitably constrained by historical conditions of the times. With the changes in the social conditions of human existence, the value of the significance of people and given the attendant change or expand and generate new era meaning, it has some kind of logical necessity. Based on this analysis, the introduction of ethical thinking in the relationship between man and nature in existence worthy of human primordial state (both natural son who is also a son of the society). Ecological ethics, although there are still a lot of controversy academia without forming more general academic consensus, but indeed has become a trend for the development of academic 
research(Radcliffe,2001).

\subsection{The Political Logic: A Top-down Conscious}

In practical level, with the depth of promoting industrial civilization, the ecological environment is deteriorating, the existence of human life on the verge of danger. At the theoretical level, scholars in various fields of ecology, philosophy, political science, etc. to further promote the study of ecological civilization problem. At the international level, the United Nations Conference on the Environment held its organizational structure, the introduction of the Universal Declaration and regulatory, warning and called for harsh environmental conditions facing humanity is to encourage countries to work together to participate and take responsibility. However, until now, eco-consciousness on the whole is far from being a global universal consensus(King .and lenox,.2001). When a spirit has not yet entered the depths of consciousness, it is difficult for the actions of consciousness. To this end, the role of the political level it is extremely necessary. Specifically speaking, the political logic consists of two levels: national indoctrination and penetration; international exchanges and cooperation.

(1)domestic indoctrination and penetration. Within a country, there are differences in the time of "eco-consciousness" of consciousness. One of the reasons include cultural values, historical traditions, educational status and ecological differences and so on. For this reason, at the political level, the state should indoctrination, infiltration and propaganda ecological awareness through education, legal, institutional and other media in various ways. Furthermore, the "eco-consciousness" evolved into "ecological view" and "ecological practices." Based on this, "ecological civilization" becoming conscious awareness throughout the national level aspirations and ideals, rather than distant "Utopia." Communist Party Congress for the first time of the "ecological civilization" written into the program of action of the party, the CPC eighteen lot "ecological civilization" building as a "five in one" included in the overall layout of socialism with Chinese characteristics, is the Chinese social and political The best evidence of implementation.

(2) international exchanges and cooperation. Unequal international political and economic order exists. Ecological conditions around the world quite different. Overall speaking, the ecological state of the US, Europe and Japan and other developed countries are far superior to the developing world. Moreover, the "ecological gap" developed and developing countries is still widening. On the one hand, developing countries are to develop the economy, but also to protect the environment; on the other hand, for its own sake, the developed countries to the developing world environmental crisis passed. Therefore, from the political level, developing countries urged the United Nations issued an international environmental rules and regulations, and strive to construct global ecological ethics. Ecological civilization level, only at the international level and the national level with each other, mutual coordination and support in order to build a real political linkage effects. Accordingly, the "ecological civilization" it could really become a global reality persists.

Of course, the "ecological civilization" to generate a three-dimensional logic is not aligned in parallel, unrelated. Among them, the reality is the basis of logic; theoretical logic is supported; political logic is guaranteed. Only these three interconnected logic, synergy, "ecological civilization" in order to ultimately generate throughout the world.

\section{Ecological Civilization Construction Paths}

Industrial civilization highlight the theme human subjectivity and passivity, which contrary to the the dialectic relationship between man and nature, If human beings suffer the disciplinary, then social development would be also unsustainable. Reflected on the industrial civilization, mankind are calling for the arrival of "ecological civilization" era. China is moving towards modernization as a large developing country, the ecological crisis is particularly serious. Therefore, in the process of development of "eco" as the focus and goal of system theory thinking and handling adjustments, including the complex relationship between man and nature, man and society and people and other aspects, is placed in us in front of a very difficult topic of the times. 


\subsection{Ideal Path: Personal Spiritual Conscious Reconstruction}

Overall speaking, the human being is the ecological crisis and the survival predicament of the instigator. Contrary to animals ,human actions but not by instinct are not dominated by instinct but ideology and consciousness (values). As Engels (1969) said the person who make a difference in the field of social history, all having awareness and well thought out or passion for the pursuit of certain actions and goals. Whatever happens, it has a conscious intent and expected purpose . For this reason, adjusting and reconstructing personal values and building eco-conscious has become "the premise of ecological civilization"at the individual level.

The so-called values, that is,the attitude towards the world of people and things which held by mankind.Generally speaking, the coexistence of diverse forms of value is the basic characteristic of our times. However, western countries have never stopped to take a variety of open or covert ways and means to strongly permeate the cultural and values to people in today's rapid globalization.The inevitable result is that Western culture and values as an exemplary stance has spread and penetrated into all countries and regions of the world, and having a strong impact and influence on the culture and values of the world, what' s more the scope and extent of its impact are remaining continuously to expand and deepen. As Weber put it, capitalism has achieved great victories today, this victory is mainly manifested in trying to universalize its own values by creating market myths and playing an exemplary leadership so that people slavishly follow its trajectory in the production and lifestyle.Specifically speaking, capitalist values include individualism,egoism, consumerism and hedonism, etc. Under the influence of these values,the individual and society, personal relationships and team relationships, human and nature have been alienated or broken up; the integrity of human life has been dismembered; materialistic obsession increasingly deepened; the ideals and beliefs have gradually forgotten. Thus, individual values will inevitably affect by the ways of thinking even behavior.

In the context of capitalist values, a serious imbalance in the ecosystem and the deterioration of the ecological crisis, making human existence has a greater degree of inevitability.Therefore, adjusting human values and building eco-ethical values become an important way to alleviate or even to save the crisis. Some scholars believe that the "new civilization will achieve an era dominated by environmental transformation shift to human transformation era, you can put a new civilization called "human Changing Times"[7].Overall speaking,there are several logically issues that individuals should realize at the level of values. Firstly person's value is based on maintaining the overall value, reflecting the priority of overall value of the ecosystem ; secondly, man and nature are inherent elements of ecosystems for their instrumental value, there is no stack up because it is a dialectical unity between the two.Thirdly, the people should shoulder important ethical responsibility on the ecosystem of nature. Objectively speaking, compared with the traditional ethics, ecological ethics is still in the "vulnerable" status for their theory contains a lot of romantic nostalgia and questioned operability.In this regard,first, I believe that generation and development of any new things are bound to experience a conflict between the old things that there is no exception in the process of ecological ethics.Second,it is fundamental that there is a process for transformation and the construction of individual values. It does this by reshaping the human spirit and soul so that the values of individual achieve a high level of awareness and freedom. Only when everyone on earth built up such a "moral imperative"can"ecological civilization" Time not only expected, but also reach.

\subsection{Practical Path: State and Society Carrot and Stick}

Currently, It is an objective fact and trends for people to enhance increasingly the ecological consciousness.However, people has not consciously construct a real and universal Ecological Ethics in the society of modernization and industrial civilization More precisely, to respect and protect the natural environment is more of a "voice"or"slogan", people has not yet become the inner spiritual consciousness and action into reality.As far as the level of Ecological Ethics, due to various historical and practical reasons lead to differences among countries regions and individuals. For this 
reason, making overall planning ,improving legal system and Strengthen moral education at the national level is an path up to enter "ecological civilization" era.

Everyone whose their thoughts and actions subject to the constraints and influence by community to a large extent. The state of the community is the highest level, the largest and its strong force,compared with families, schools, communities and nations.Therefore,taking systematic global concept as a guide to develop the concept of the relationship between man and society, man and nature, man and man, co-ordinating the development of ideas of departments, enterprises and regions build a "holistic Ecological Ethics" as the core of Social Development.This top-level concept design at the national level is extremely important, as it can play a leading role on Ecological Ethics among society, enterprises and individuals.

In the promoting of the market economy,the most fundamental principle of personal and business activities is the "self-interest maximization."Under the domination of this principle, personal and corporate events detached from society and nature, causing external diseconomies and deepen contradiction between man and nature. Thus, in the country as a social level include the following two aspects: there are two methods to solve issues at the level of society first, through the development and improvement of the legal system of rules can we supervise, norms and discipline uneconomic ecological behavior of individuals, businesses, and so on.that is intervened by rigid legal system, then gradually standardized the individual and the enterprise's economic activity so that the social and ecological interests ahead of individual interests.National Science and Technology should be placed in natural ecosystems to regulate and manage. It is wise to encourage individuals and enterprises engaged in innovation, such as"green technology" or "eco-technology" and other aspects of the promotion and use of environmentally friendly technologies.Second, eco-consciousness first began in the political and academic levels. Therefore, the development and dissemination of unified universality and particularity ecological ethical values norms is necessary.Therefore, the state should build the appropriate value of ecological ethics norms at political level.Individuals and businesses gradually taking ecological values to their spiritual world through the guide of mass media, social activities and education, then making them pay attention to their social and ecological benefits in economic activities.

\subsection{Global Path: International Exchanges and Cooperation}

Any one country or region live in this earth ecosystem. Overall speaking, the Earth's ecological degradation and human survival distress is a common cause of all countries. Of course, Western countries should bear more"historical responsibility"due to the complex variety of historical and practical reasons.In a globalized world, the fate of mankind is more closely linked together.Development of any country and region of the Earth's ecosystems are inseparable. Therefore, creating a"ecological civilization" in the new era is inseparable of exchanges and cooperation from the every countries and regions.Specifically speaking, includes the following two aspects:

First of all, the United Nations is a international organization which has the functions of leadership, organization, coordination and supervision in international affairs. The United Nations has introduced a number of regulations and documents for environmental issues since The UN hosted a Conference on the Environment for the first time in human history.It called on all countries to participate,work together and share the responsibility in environmental issues for a better future of mankind. Objectively speaking, the role of the United Nations is becoming important in promoting and coordinating the concerned human issues.However, since the United Nations organization is contractual, its most important role is appealing and coordination rather than leadership and supervision, That is, in a sense,the United Nations has no right to criticize and punish Western countries which ever created the "environmental sins."And in many cases, the United Nations has been kidnapped in developed countries, these countries are forced to become to the accomplice of "environmental sins". Furthermore, the international political and economic order is still unequal to develop in depth, contrast between developed and developing countries on environmental issues is still widening. 
Secondly, each sovereign state should strengthen international cooperation and communication . There are differences between countries and regions in the development of economy, politics, culture and other aspects.Therefore, there are differences in perception and understanding in the environmental crisis, ecological awareness, ecological civilization construction and other issues Thus, each sovereign state or region should be based on their actual situation to construct appropriate strategies of ecological civilization.If every country and region can put into action, then,they will form a international recognition and consensus in the Ecological Ethics and ecological civilization construction in the near future.

Form a macroeconomic point of view, the process of saving the ecological crisis and building ecological civilization consists of three dimensions that mainly included conscious in individual level of values, carrot and stick in national level and and cooperation of international level.Three dimensions are interconnected, intertwined and synergy.First, the values of the level of consciousness is ideal. However,there is a relatively long process for building the conscious of environmental protection, which requires the top catalysis from the social dimension and international level;Second, to improve legal system and strengthen moral education is realistic level. Because there are differences in the value of cognitive and construct status among levels of individual countries and regions.Therefore it is urgent to achieve the norm of legal system and the guide of moral education in the real level Third, global communication and cooperation is the highest level $\mathrm{f} r$ building ecological civilization.it also can promote the construction of global ecological values through interaction internationally.

Furthermore, every country should based on their national circumstances that taking a more universal global ecological values as a guide to build a relatively particular ecological values and to achieve the construction of ecological civilization finally.

\section{Conclusion}

Various academic and political debate About ecological civilization has never stopped since the concept was put forward. In social life, the people's ecological awareness is growing with the further deterioration of the existential crisis and ecological environment. showing the destruction of the ecological environment of the actors give strong condemnation and requirements to improve the ecological environment of It is a increasingly strong voice people give strong condemnation and requirements to improve the ecological environment on disruptive behavior.Objectively speaking, due to a variety of historical and practical reasons, the overall ecological awareness, ecological and environmental conditions in developed countries is far superior to the developing world.Thus,conflicts between economic development and environmental protection are more prominent,and ecological civilization construction of the road is more difficult, more lengthy for developing countries.The author believes that it is extremely important to strengthen international exchanges and dialogue between the developing countries alleviating the acute contradiction between economic development and environmental protection, as well as regional ecological civilization construction worldwide. Developed countries should shoulder the historical responsibility on ecological and environmental problems, providing financial, technical and human support in environmental management, environmental protection, green technology and recycling economy and other aspects.However, the most pressing issue is developing the ecological civilization-oriented, adjusting and changing of the structure of economic and social development in the sovereign state, which is the mos critical and realistic to solve ecological contradictions and ease the crisis of survival.

Currently, the "ecological civilization" is still an ideal of terminology, such era are not under our feet but in the near or distant future. I believe that Marx's views and ideas are still worthy of further reflection today. That is, the occasional achievement of "ecological civilization"is possible.However, only when revolutionize today's production and social system can we achieve the universality of the ecological within the scope of the entire planet. As Marx put it,"the communism as completion of naturalism equals humanism as completed humanitarian equal to naturalism,which is the real 
solution to solve conflicts between man and nature."(Marx)Of course, we have no reason not to expect and strive for that as the most initiative specie on the earth .

\section{Acknowledgments}

Collaborative Innovation Center of Beijing College about Chinese characteristics socialism research ( Capital Normal University )Marxism and Contemporary Chinese Literature Construction Project (PXM2016_014203_000107)

\section{References}

[1] Commoner， B.1997, Closed loop. Changchun: Jilin People's Publishing House.

[2] Daniel B. 1985, The Culture Contradiction of Capitalism, Basic Book.

[3] Foster.J B.2000, Marx's ecology: materialism and nature. New York:Monthly Review Press.

[4]Hegel,G.2004, Little Logic, Beijing: Commercial Press.

[5]Holmes R.1994, Value in Nature and the Nature of Value.Cambridge:Cambridge

[6]Labor P.1973,Politics of the Environment,London: Labor Party.

[7]Lowi.M R. and Shaw.B R.2000,Environment and Security.S.T.Maritirts Press.

Marx and Engels. 1965,Complete Works of Marx and Engels, Vol. 42, Beijing: People's Publishing Press.

[8]Mumford, L.1983 Techies and the Nature of Man In Philosophy and Technology, ed.by C.Mithcham. New York, The Free Press.

[9]King,A.and lenox, M.2001.Does it really pay to be Green?Accounting for Strategy Selection in the Relationship between Environmental and Financial Performance. Journal of Industrial Ecology,(4).

[10]Passmore.J.1974,Man's Responsibility for Nature.New York:Ecological Problems and Western Traditions.

[11]Spyke.N P.1999 , Public Participation in Environmental Decision making at the New Millennium:Structuring New Spheres of Public Influence,26B.C.Envtl.Aff.L.Rev.263.

[12]Richard S and David B.1988, “Taoism and Deep Ecology” ,The Ecology,No.18.

[13]Radcliffe,J.2001,Green Politics: Dictatorship or Democracy?,Great Britain :Macmilian Press TMD.

[14]Taylor.P. W. 1986, Respect for nature. Princeton University Press.

[15]The Commission on Global Governance.2007,Our Global Neighborhood.Oxford and York:Oxford

[16]WEF.2002,Environmental Performance Measurement: The Global Report 20012002.Ceneva, Switzerland; World Economic Forum.

[17]Yan, G and Yang, Z H.2009, the construction of ecological civilization and systems theory, the Central Compilation and Translation Press. 